\title{
Evaluating Performance of Magnesium Oxide at Different Sizes as Activator for Natural Rubber Vulcanization
}

\author{
Siti Nor Qamarina M., and S. Kawahara
}

\begin{abstract}
It is generally known that activator containing zinc-compounds has been extensively used in the rubber industry due to its outstanding ability in promoting beneficial effects to the rubber products. Ever since these compounds were identified having negative environmental effects as well as contributing to mould fouling during rubber products manufacturing, various approaches have been considered by the rubber manufacturers in reducing its utilization. Among all the alternatives proposed, an approach of utilizing magnesium oxide $(\mathrm{MgO})$ seems to be promising. A lot of research has been conducted on the performance of the typical $\mathrm{MgO}$ in affecting natural rubber (NR) vulcanizates, but limited works had been performed in evaluating the activating properties of the nano-sized $\mathrm{MgO}$ in NR. Therefore, in this study, affects $\mathrm{MgO}$ sizes at various loadings on the vulcanization reaction and vulcanizates properties of NR are investigated. The normally used zinc-containing compound was employed as an activator in the vulcanization of NR for comparison purposes. Gauging on the cure characteristics, it was found that nano-sized $\mathrm{MgO}$ performed better; as it exhibited faster onset time, lower cure time $\left(\mathrm{t}_{90}\right)$ with greater physical properties, as compared to the typical $\mathrm{MgO}$. Morphological observations on images taken from scanning electron microscope (SEM) and transmission electron microscope (TEM) analysis demonstrated that nano-sized $\mathrm{MgO}$ appeared in smaller aggregates with even aggregates distributions throughout the rubber matrix, in comparison to the aggregates behavior of the typical $\mathrm{MgO}$. The aggregates for both sizes of $\mathrm{MgO}$ particles were found intensified with higher amount of $\mathrm{MgO}$ present in the vulcanization system, which accounted for reversion in the NR vulcanizate performances. Although the overall performance of the nano-sized $\mathrm{MgO}$ in NR vulcanization surpassed the typical $\mathrm{MgO}$ used in the similar discipline; nevertheless, the findings obtained were to some extent lower in comparison to the NR vulcanizate performance containing normally used zinc-containing compound. On the whole, $\mathrm{MgO}$ has some ways behaved as the zinc-containing compound, but the role of the $\mathrm{MgO}$ as an alternative activator for $\mathrm{NR}$ vulcanization should be further investigated, specifically for the nano-sized $\mathrm{MgO}$ in enhancing its reactivity within the NR compounds.
\end{abstract}

Index Terms - Magnesium Oxide, Particle Size, Natural Rubber, Vulcanization, Physical Performances, Morphology

\section{INTRODUCTION}

Magnesium oxide $(\mathrm{MgO})$ is a well-known material to be thermally stable due to its stoichiometric-crystalline form, which is like a simple sodium chloride structure. It is anticipated that its presence in nano-sized may impose greater

Manuscript received on March 28, 2016. This work is a part of research work conducted at Nagaoka University of Technology, Japan. This work was financially supported by Malaysian Rubber Board.

Siti Nor Qamarina $\mathrm{M}$ is working with the Technology and Engineering Division of the Malaysian Rubber Board, 47000 Sg. Buloh, Malaysia

S. Kawahara is currently with Nagaoka University of Technology, Japan. He is now with the Department of Material Science, Faculty of Engineering potential as the nano-sized $\mathrm{MgO}$ particles may offer larger surface area as compared to the conventional $\mathrm{MgO}$ [1-2]. The nano-size $\mathrm{MgO}$ crystalline-like structure will exhibit remarkable reactivity in accelerating reactions as a catalyst, for instance in rubber manufacturing besides enabling them to act as filler for rubber products [2]. Specifically, the nano-sized $\mathrm{MgO}$ will form active sulfurating agents and activate the crosslinking formation between the rubber particles during vulcanization, as the normally used activator executed in the rubber vulcanization process. While offering greater sites for acceleration reactions during rubber vulcanization, the nano-sized $\mathrm{MgO}$ might exhibit as a potential suitable alternative metal activator for the rubber vulcanization.

Availability of boundless source of $\mathrm{MgO}$ from seawater and brine has made it identified as the third most abundant element. Therefore, exploiting the beneficial properties of the $\mathrm{MgO}$ is useful for many areas, including rubber technology. Generally, fabricating nano-sized $\mathrm{MgO}$ for rubber products manufacturing was initiated attributed to the increase concern in protecting the environment. Previously, zinc oxide $(\mathrm{ZnO})$ was used to catalyze rubber vulcanization process. Its mechanism during vulcanization process $[4,8,9,12]$ and its effects on the properties of the vulcanizates [3-7,9,11] has long been known and investigated. However, $\mathrm{ZnO}$ release into the environment that occurs during production, disposal and recycling of rubber products, which is in soluble zinc compounds is classified as ecotoxic to aquatic organisms [5,7,9-10]. Moreover, usage of $\mathrm{ZnO}$ is also associated with a problem related to mold fouling that occurs during rubber manufacturing [9,13-14]. There is evidence that during vulcanization, a considerable amount of $\mathrm{ZnO}$ is consumed and transformed into zinc sulfide $(\mathrm{ZnS})$, which is a by-product of the vulcanization reactions. Distributions of un-dissolved $\mathrm{ZnS}$ particles formed inhomogeneity within the rubber matrix [15]. These inhomogeneities have been reported lead to mold fouling of the rubber products. As consequences, many efforts have been put into considerations in minimizing the $\mathrm{ZnO}$ content in rubber products manufacturing to ensure low pollution impact, nonetheless at tolerable manufacturing cost.

Among numerous numbers of investigations comparing different metal oxides as rubber vulcanization activators, considering the usage of $\mathrm{MgO}$ as an environmentally friendly activator for rubber vulcanization is worthwhile. It is anticipated that replacement of the $\mathrm{ZnO}$ with the $\mathrm{MgO}$ resulted in promising characteristics, since $\mathrm{Zn}^{2+}$ and $\mathrm{Mg}^{2+}$ have equal charges. Furthermore, the $\mathrm{MgO}$ presence in nano-sized particles will offer greater surface area for vulcanization reaction. Therefore, in this study, the effects of the nano-sized $\mathrm{MgO}$ in curing, mechanical properties and morphology of the rubber vulcanizates are evaluated in order to understand the 
nano-sized $\mathrm{MgO}$ effectiveness in the sulfur vulcanization process while elucidating a relationship between the hierarchal structure and the vulcanizates properties achieved.

\section{EXPERIMENTAL}

\section{A. Material}

Natural Rubber (NR) grade of SMR 20, obtained from Yokohama Rubber Japan was used throughout this study. Other compounding ingredients such as sulfur and $\mathrm{ZnO}$ was purchased from Nacalai Tesque Inc. Tetramethyl thiuram disulphide (TMTD) and stearic acid from TCI/EP; N-tertiary butyl-2- benzothiazole sulfonamide (TBBS) and conventional $\mathrm{MgO}$ (micro-sized) were from Wako Chemicals; while Tokuyama Soda Co. Ltd supplied the nano-sized MgO. All the materials were of commercial grades and used as such.

\section{B. Preparation of Rubber Compounds}

The rubber compounds contained various loadings of different $\mathrm{MgO}$, as activator was prepared, as tabulated in Table I. The control rubber compound containing fixed amount of normally used $\mathrm{ZnO}$ as activator was used as control. All the NR batches were prepared using laboratory internal mixer (Toyoseiki Labo Plastomill 4M150). The rubber mixings were carried out in accordance to ASTM D-3192. The internal mixer was set to working at $50^{\circ} \mathrm{C}$ with rotor speed of $60 \mathrm{rpm}$.

TABLE I

COMPOSITION OF RUBBER COMPOUNDS (IN PHR) A: $2,4,12,20$

\begin{tabular}{lccc}
\hline \hline Composition & Nano-size & Typical-size & Control \\
\hline SMR20 & 100 & 100 & 100 \\
ZnO & - & - & 2.0 \\
Stearic acid & 1.5 & 1.5 & 1.5 \\
TBBS & 1.9 & 1.9 & 1.9 \\
TMTD & 0.9 & 0.9 & 0.9 \\
MgO & $\mathrm{a}$ & $\mathrm{a}$ & - \\
Sulphur & 2.2 & 2.2 & 2.2 \\
\hline \hline
\end{tabular}

C. Analysis of Rubber Vulcanizates

Cure Characteristic: The cure characteristics of rubber compounds were measured using Toyoseiki Rotorless Rheometer RLR-4 at $150^{\circ} \mathrm{C}$. The optimal vulcanization time, $\mathrm{t}_{90}$ were determined. The compounds were cured using laboratory press at $150^{\circ} \mathrm{C}$ according to $t_{90}$ for the specific compounds. The compounds were sheeted off at a thickness of $1 \mathrm{~mm}$.

Physical Properties Analysis: Dumbbell-shaped samples were cut from the mould sheet according to JIS K6251 (type 7). Tensile properties were determined via an Instron 3300 testing machine with a crosshead speed of $200 \mathrm{~mm} / \mathrm{min}$.

Morphological Observation: Observation on the rubber vulcanizates compositional difference was carried out using focused ion-beam/scanning electron microscopy (FIB/SEM) technique (JEOL Ltd. Japan; Model SMI 3050 SE). The FIB is first used to ion mill a trench on the vulcanizates surface, of which the thickness is around $100 \mathrm{~nm}$ will be removed; followed by SEM imaging on the exposed area to obtain its morphological information. In order to understand the rubber vulcanizate internal characteristic, transmission electron microscopy (TEM) of JEOL JEM-2100 at an accelerating voltage of $20 \mathrm{kV}$ was used. Ultrathin sections with a thickness about 50-100 $\mathrm{nm}$ were first prepared at $-90^{\circ} \mathrm{C}$ using a
Richert-Nissei FC S-Ultracut before conducting the observation.

\section{RESUlTS AND DiscUSSION}

Cure curves for various NR compounds at different sizes of $\mathrm{MgO}$ were illustrated in Fig. 1a and 1b. Overall, the cure curves for the nano-sized $\mathrm{MgO}$ and the typical $\mathrm{MgO}$ were lower in comparison to the normally used $\mathrm{ZnO}$, as represented in Fig. 1a and Fig.1b, respectively. Both of the cure curves agreed that increased content of the $\mathrm{MgO}$ would increase the torque value for a specific period of time before truncated. In conjunction with that, it was also noticed that the cure time $\left(t_{90}\right)$ of the NR compounds in the presence of the $\mathrm{MgO}$ were found to some extent lower than the NR compound with $\mathrm{ZnO}$ utilization. It was reported that $\mathrm{MgO}$ possess slightly slow rate of cure during vulcanization reaction [2-6], hence lower $t_{90}$ values achieved for $\mathrm{NR}$ compounds with $\mathrm{MgO}$ loadings were much expected.

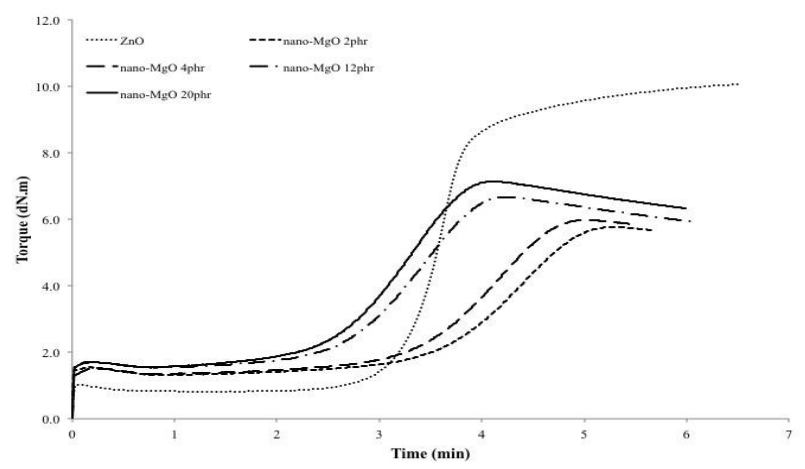

Fig. 1a. NR compounds cure curves with nano-sized $\mathrm{MgO}$ at various loadings

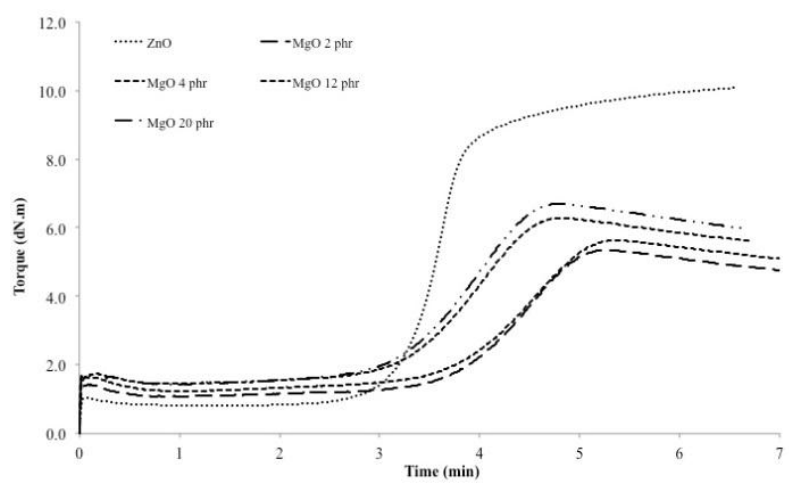

Fig. 1b. NR compounds cure curves with typical $\mathrm{MgO}$ at various loadings

Meanwhile, the $\mathrm{MH}$, which can be regarded as a measure of modulus were found increased with increased of the $\mathrm{MgO}$ loadings and similar trend was observed on the ML values, which represent the rubber compounds' viscosity behavior. Furthermore, it was apparent that the cure curves of NR compounds with $\mathrm{MgO}$ contents showed significant shift once the NR vulcanizate contained 12 and $20 \mathrm{phr}$ of the $\mathrm{MgO}$ loadings. The results might suggest that higher amount of $\mathrm{MgO}$ is necessary to catalyze an enhancement in the vulcanization reaction. 
The sudden increased or defined as the onset time for vulcanization was found faster in the NR vulcanizate with nano-sized $\mathrm{MgO}$ as activator. It was appeared at 2 minutes, while the NR vulcanizatess with typical $\mathrm{MgO}$ and the normally used $\mathrm{ZnO}$ activator have an onset time after 3 minutes. These results showed the ability of the $\mathrm{MgO}$ in activating the vulcanization process of the NR compounds besides suggesting that nano-sized $\mathrm{MgO}$ attained faster onset time due to greater sites offered for the vulcanization interaction to take place.

Stress-strain $(\sigma / \gamma)$ curves of rubber compounds activated by the nano-sized $\mathrm{MgO}$ and the typical $\mathrm{MgO}$ were shown in Fig. 2a and Fig. 2b, respectively. Apparently, NR vulcanizates with nano-sized $\mathrm{MgO}$ has $15 \%$ longer strain, as compared to the NR vulcanizates with the typical $\mathrm{MgO}$. Overall, NR vulcanizates demonstrated a recoverable extension within $\gamma<5$ before ruptured. The $\sigma / \gamma$ curves between low and high loading amount of the nano- $\mathrm{MgO}$ demonstrated a big gap between the curves (Fig. 2a). The significant disparity was anticipated due to the effect of strain-induced crystallization [16]. Greater amount of the nano-sized $\mathrm{MgO}$ available during vulcanization might offer better interaction between the chemicals during vulcanization, which in the end affect the elongation of crosslinks formed in the vulcanizates. On the other hand, NR vulcanizates with the typical $\mathrm{MgO}$ illustrated limited vulcanizates extension. The size of the $\mathrm{MgO}$ was presumed to be one of a factor that restricted the extensibility of the vulcanizates to elongate, hence causing a breakage at relatively small deformation [17].

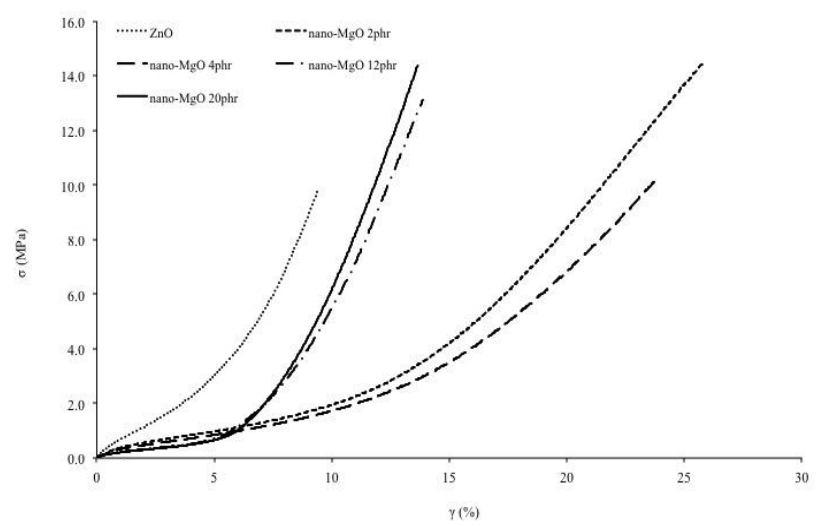

Fig. 2a. Stress-strain curves contained nano-sized $\mathrm{MgO}$ at various loadings

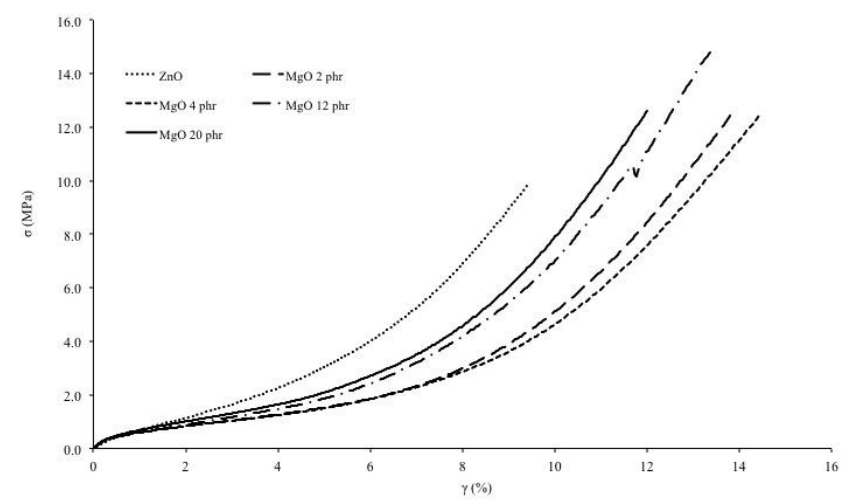

Fig. 2b. Stress-strain curves contained typical $\mathrm{MgO}$ at various loadings

The physical properties of the NR vulcanizates, which contained different type of activator at varied loadings, were listed in Table II. Although NR vulcanizates contained $\mathrm{MgO}$ illustrated lower physical performances as compared to the NR vulcanizates with $\mathrm{ZnO}$ as activator; it's worth affirmed that the $\mathrm{NR}$ vulcanizates with $\mathrm{MgO}$ portrayed longer extension before ruptured. Low tensile strength and $\mathrm{M}_{300}$ values of $\mathrm{NR}$ vulcanizates achieved in the presence of $\mathrm{MgO}$ could be related to low activation energy of the $\mathrm{MgO}$. Due to this, greater heterogeneities have been created during the vulcanization reaction, which in the end intensified the ruptured potential of the NR vulcanizates [18].

TABLE II

Physical PROPERTIES OF RUBBer VULCANIZATES With DifFERENT TyPe OF ACTIVATOR AT VARIED LOADINGS

\begin{tabular}{|c|c|c|c|}
\hline Activator & $\begin{array}{c}\text { Tensile strength } \\
\text { (MPg) }\end{array}$ & $\begin{array}{l}\mathrm{M}_{900} \\
(\mathrm{MPg})\end{array}$ & $\begin{array}{c}\text { Elongation at } \\
\text { break }(\%)\end{array}$ \\
\hline Control & 17.5 & 2.74 & 59 \\
\hline $\begin{array}{l}\text { Nano-size } \mathrm{MEQ} \\
\text { - } 2 \mathrm{ghr} \\
\text { - } 4 \mathrm{ghr} \\
\text { - } 12 \mathrm{ghr} \\
\text { - } 20 \mathrm{phr}\end{array}$ & $\begin{array}{l}12.7 \\
13.7 \\
14.3 \\
15.0\end{array}$ & $\begin{array}{l}0.75 \\
0.68 \\
0.41 \\
0.39\end{array}$ & $\begin{array}{l}251 \\
245 \\
139 \\
135\end{array}$ \\
\hline $\begin{array}{l}\text { Typical-size XIgQ } \\
\text { - } 2 \mathrm{ghr} \\
\text { - } 4 \mathrm{ghr} \\
\text { - } 12 \mathrm{ghr} \\
\text { - } 20 \mathrm{phr} \\
\end{array}$ & $\begin{array}{l}12.4 \\
12.4 \\
12.7 \\
12.4\end{array}$ & $\begin{array}{l}0.95 \\
1.03 \\
1.14 \\
1.33\end{array}$ & $\begin{array}{l}138 \\
141 \\
136 \\
109\end{array}$ \\
\hline
\end{tabular}

In order to understand the distribution of the activator within the rubber matrix, morphological observation through FIB/SEM technique was conducted. Fig. 3 represents the inner structure of NR vulcanizate in the presence of $2 \mathrm{phr} \mathrm{ZnO}$. The bright domains, which is known as $\mathrm{ZnO}$-aggregates complexes were found apparently distributed within the rubber matrix. Comparison of inner structure between the NR vulcanizates in the presence of $\mathrm{ZnO}$ and nano-sized $\mathrm{MgO}$ showed that $\mathrm{NR}$ vulcanizate with nano-sized $\mathrm{MgO}$ portrayed better interaction with the rubber matrix (Fig. 4a). However, greater aggregates complexes were observed distributed within the rubber matrix once the nano-size $\mathrm{MgO}$ were abundantly present in the system (Fig. 4b).

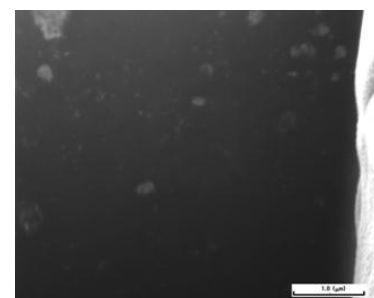

Fig. 3. FIB/SEM image of NR vulcanizate in the presence of $\mathrm{ZnO}$ at 2

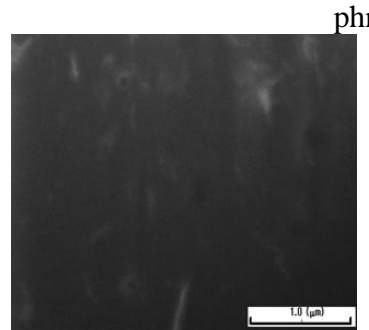

(a) phr

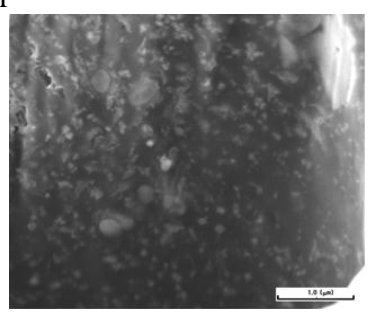

(b)

Fig. 4. FIB/SEM images of NR vulcanizate in the presence of nano-sized $\mathrm{MgO}$ at (a) $2 \mathrm{phr}$ and (b) $20 \mathrm{phr}$

In contrast, the inner surface of the NR vulcanizates contained typical $\mathrm{MgO}$ were found to comprise noticeable 
amount of bright domains within the rubber matrix even at 2 phr loading (Fig. 5a). The aggregates complexes were intensified and grow in size at higher typical $\mathrm{MgO}$ content (Fig. $5 b)$. These aggregates were responsible to the decrease in the mechanical properties of the NR vulcanizates as they will act as sources of fracture, which led to the elasticity disturbance of the NR.

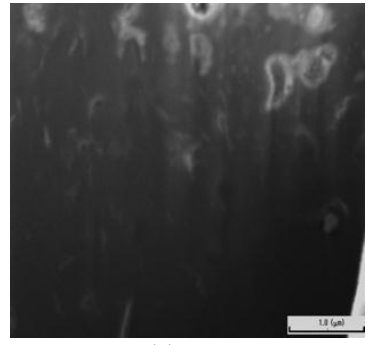

(a)

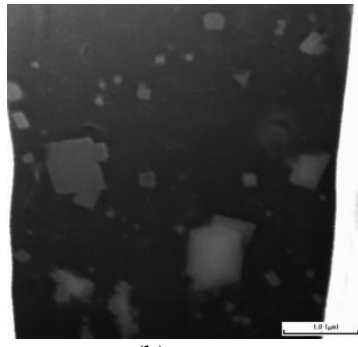

(b)

Fig. 5. FIB/SEM images of NR vulcanizate in the presence of typical $\mathrm{MgO}$ at (a) $2 \mathrm{phr}$ and (b) $20 \mathrm{phr}$

TEM images for the NR vulcanizate in the presence of $\mathrm{ZnO}$, nano-sized $\mathrm{MgO}$ and typical $\mathrm{MgO}$ were shown in Fig. 6Fig. 8, respectively. The bright domain represents the rubber matrix, while the dark domains were the activator-complexes aggregates. It was appeared that size of activator-complex aggregates dependent on the size and the loading amount of the activator. The images obtained from TEM technique were well agreed with the SEM images and the physical properties achieved.

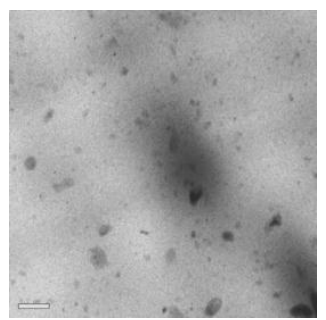

Fig. 6. TEM image of NR vulcanizate in the presence of $\mathrm{ZnO}$ at $2 \mathrm{phr}$

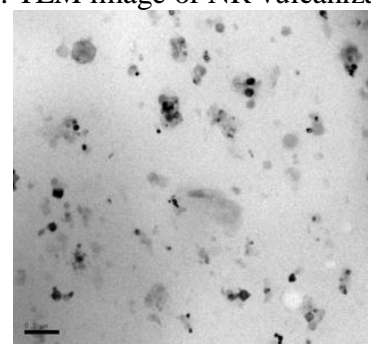

(a)

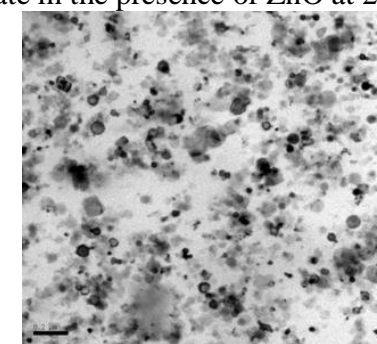

(b)

Fig. 7. TEM images of NR vulcanizate in the presence of nano-sized $\mathrm{MgO}$ at (a) $2 \mathrm{phr}$ and (b) $20 \mathrm{phr}$

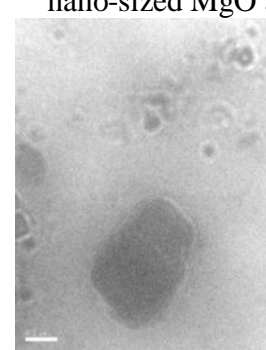

(a)

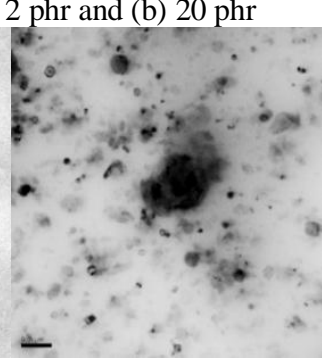

(b)
Fig. 8. TEM images of NR vulcanizate in the presence of typical $\mathrm{MgO}$ at (a) $2 \mathrm{phr}$ and (b) $20 \mathrm{phr}$

\section{CONCLUSION}

The utilization of nano-sized $\mathrm{MgO}$ as an activator for $\mathrm{NR}$ compound was found performed better in curing with acceptable physical properties values and portrayed a good particle distribution in the rubber matrix, in comparison to the typical MgO. Even though the final NR vulcanizates properties of this material were to some extent lower than the $\mathrm{ZnO}$ vulcanizates, nevertheless the findings obtained proved that this nano-sized $\mathrm{MgO}$ is still capable to activate the vulcanization process with faster onset time. At present, the nano-sized $\mathrm{MgO}$ can be considered as an alternative activator for NR vulcanization. However, exploring approaches in optimizing the nano-sized $\mathrm{MgO}$ functionality for $\mathrm{NR}$ vulcanization, with an aimed replacing $\mathrm{ZnO}$ utilization shall be thoroughly conducted for our future benefits.

\section{ACKNOWLEDGMENT}

The author thanks every personnel for their continuous assistance and support throughout her research work.

\section{REFERENCES}

[1] Shand, M.A., The Chemistry and Technology of Magnesia, Chap. 8, Ohio: John Wiley \& Sons Inc., 2006, pp. 121.

[2] Khairaallah, F. and Glisenti, A., "Synthesis, Characterization and Reactivity Study of Nanoscale Magnesium Oxide", J. Molecular Catalysis: A Chemical, vol. 247, pp. 137-147, 2007.

http://dx.doi.org/10.1016/j.molcata.2007.04.039

[3] Heideman, G., Noordemeer, J.W.M., Datta, R.N., Enschede, van Baarle, B. and Eindhoven., "Effect of Metal Oxides as Activator for Sulphur Vulcanization in Various Rubbers", KGK Kautschuk Gummi Kunststoffe, vol. 58, pp. 30-42, 2005.

[4] Guzman, M., Reyes, G., Agullo, N., and Borros, S. "Synthesis of Zn/Mg Oxide Nanaoparticles and Its Influence on Sulfur Vulcanization", J. App. Poly. Sci., vol. 119, pp. 2048-2057, 2011 http://dx.doi.org/10.1002/app.32885

[5] Heideman, G., Nooedermeer, J.W.M., Datta, R.N., and van Baarle, B., "Various Ways to Reduce Zinc Oxide Levels in S-SBR Rubber Compounds", Macromol. Symp., vol. 245-246, pp. 657-667, 2006. http://dx.doi.org/10.1002/masy.200651393

[6] Kar, S., and Bhowmick, A.K., "Nanostuctured $\mathrm{MgO}$ as Cure Activator for Chloroprene Rubber", J. Nanoscience and Nanotech, vol. 9, no. 5, pp. 3144-3153, 2009. http://dx.doi.org/10.1166/jnn.2009.005

[7] Chapman, A.V., "Safe Rubber Chemicals: Reduction of Zinc Levels in Rubber Compounds", presented at TARRC/MRPRA Symposium, 1997.

[8] Coran, A.Y., "Chemistry of the Vulcanization and Protection of Elastomers: A Review of the Achievements", J. App. Poly. Sci., vol. 87, pp. 24-30, 2003. http://dx.doi.org/10.1002/app.11659

[9] Heideman, G., Datta, R.N., Noordermeer, J.W.M., and van Baarle, B., "Influence of Zinc Oxide during Different Stages of Sulfur Vulcanization. Elucidated by Model Compound Vulcanization”, J. App. Poly. Sci., vol. 95, pp. 1388-1404, 2005.

http://dx.doi.org/10.1002/app.21364

[10] Guzman, M., Peyes, G., Agullo, N., and Borros, S., "Zinc Oxide versus Magnesium Oxide Revisits: Part 2", Rubb. Chem. Technol., vol. 85, pp. 56-67, 2012. http://dx.doi.org/10.5254/1.3672429

[11] Guzman, M., Peyes, G., Agullo, N., and Borros, S., "Zinc Oxide versus Magnesium Oxide Revisits: Part 2", Rubb. Chem. Technol., vol. 85, pp. 38-55, 2012. http://dx.doi.org/10.5254/1.3672429

[12] Przybyszewska, M., Zaborski, M., Jakubowski, B., and Zawadiak, J., "Zinc Chelates as NewZactivators for Sulphur Vulcanization of Acrylonitrile-Butadiene Elastomer", eXPRESS Polymer Letters, vol. 3, pp. 256-266, 2009.

http://dx.doi.org/10.3144/expresspolymlett.2009.32 
[13] Dohi, H., and Horiuchi, S., "Heterogeneity of a Vulcanized Rubber by the Formation of ZnS Clusters", Polymer, vol. 48, pp. 2526-2530, 2007. http://dx.doi.org/10.1016/j.polymer.2007.03.004

[14] Niuwenhuizen, P.J., Ehlers, A.W., Haasnoot, J.G., Janse, S.R., Reedjick, J., and Baerands, E.J., "The Mechanism of Zinc(II)-Dithiocarbamate-Accelerated Vulcanization Uncovered", $J$. Amer. Chem. Soc., vol 121, pp. 163-168, 1999. http://dx.doi.org/10.1021/ja982217n

[15] Ikeda,Y., Kohjiya, S., Katoh, A., Shimanuki, J. and Hasegawa, T., "Three-Dimensional Nano-Structure of In-situ Silica in Natural Rubber as Revealed by 3D-TEM/Electron Tomography", Polymer, vol. 46, pp. 4440-4446, 2005. http://dx.doi.org/10.1016/j.polymer.2005.02.026

[16] Sperling, L.H., Introduction to Physical Polymer Science, Chap. 11, Pennsylvania: John Wiley \& Sons, Inc., 2001, pp. 477.

[17] Teh, P.L., Mohd. Ishak, Z.A., Hashim, A.S., Karger-Koscis, J., and Ishiaku, U.S., "Effect of Epoxidized Natural Rubber as a Compatibilizer in Melt Compounded Natural Rubber", Euro. Polym. J., vol. 40, no. 11, pp. 2515-2521, 2004. http://dx.doi.org/10.1016/j.eurpolymj.2004.06.025

[18] Gent, A.N., Science and Technology of Rubber, Chap. 5, London: Academic Press, 1994, pp. 472.

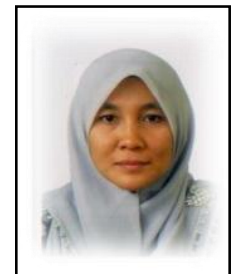

Siti Nor Qamarina M. was born in state of Kedah, the northern part of Malaysia in 1982. She obtained her first degreee in Applied Chemistry (Analytical) from University Sains Malaysia (USM), Malaysia in 2008. In 2012, she received her Master of Engineering (Material Science and Technology) from Nagaoka University of Technology, Japan.

Currently, she is one of a research officer in the Development and Improvement of Latex Products of Malaysian Rubber Board (MRB). For the previous 10 years, her focused primarily encompassed on research and development of natural rubber latex (NRL)-based products. At present, her research interest associated with colloidal science approaches in developing innovative NRL-based products. She has authored several publications and conference papers on various aspects related to science and technology of NRL-based products, both locally and internationally. 